\title{
Dynamic Interactions Between Plasma IL-I Family Cytokines and Central Endogenous Opioid Neurotransmitter Function in Humans
}

\author{
Alan R Prossin*, 1,2 , Steven S Zalcman ${ }^{3,4}$, Mary M Heitzeg ${ }^{1}$, Alisa E Koch ${ }^{4,5}$, Phillip L Campbell, \\ K Luan Phan ${ }^{1,6}$, Christian S Stohler ${ }^{7}$ and Jon-Kar Zubieta ${ }^{1,8,9}$ \\ 'Department of Psychiatry, University of Texas Health Science Center at Houston, Houston, TX, USA; '2Department of Symptom Research, \\ University of Texas MD Anderson Cancer Center, Houston, TX, USA; ${ }^{3}$ Department of Psychiatry, New Jersey Medical School, University of \\ Medicine and Dentistry of New Jersey, Newark, NJ, USA; ${ }^{4}$ Medical Service, Veteran's Administration Ann Arbor, Ann Arbor, MI, USA; ${ }^{5}$ Department \\ of Internal Medicine, Division of Rheumatology, University of Michigan Medical School, Ann Arbor, MI, USA; ${ }^{6}$ Department of Psychiatry, University \\ of Illinois at Chicago, Chicago, IL, USA; ${ }^{7}$ Columbia College of Dental Medicine, New York, NY, USA; ${ }^{8}$ Molecular and Behavioral Neuroscience \\ Institute, University of Michigan Medical School, Ann Arbor, MI, USA; ' Department of Radiology, University of Michigan Medical School, \\ Ann Arbor, MI, USA
}

\begin{abstract}
Evidence in animal models suggests IL-I family cytokines interact with central endogenous opioid neurotransmitter systems, inducing or perpetuating pathological states such as persistent pain syndromes, depression, substance use disorders, and their comorbidity. Understanding these interactions in humans is particularly relevant to understanding pathological states wherein this neurotransmitter system is implicated (ie, persistent pain, mood disorders, substance use disorders, etc). Here, we examined relationships between IL-I $\beta$, $\mathrm{IL}-\mathrm{I}$ ra, and functional measures of the endogenous opioid system in 34 healthy volunteers, in the absence and presence of a standardized sustained muscular pain challenge, a psychophysical challenge with emotionally and physically stressful components. Mu-opioid receptor availability in vivo was examined with [ ' $\mathrm{C}$ ]carfentanil positron emission tomography (PET) scanning. Sex and neuroticism impacted IL-I family cytokines; higher baseline IL-I $\beta$ and IL-I ra was identified in females with lower neuroticism. Higher baseline IL-I $\beta$ was also associated with reduced $\mu$-opioid receptor availability (amygdala) and greater pain sensitivity. The pain challenge increased IL-I $\beta$ in females with high neuroticism. Strong associations between IL-Ira (an anti-nociceptive cytokine) and $\mu$-opioid receptor activation (VP/NAcc) were identified during the pain challenge and the resulting analgesic effect of $\mu$-opioid receptor activation was moderated by changes in IL-I $\beta$ whereby volunteers with greater pain induced increase in IL-I $\beta$ experienced less endogenous opioid analgesia. This study demonstrates the presence of relationships between inflammatory factors and a specific central neurotransmitter system and circuitry, of relevance to understanding interindividual variations in regulation of responses to pain and other physical and emotional stressors.
\end{abstract}

Neuropsychopharmacology (20I5) 40, 554-565; doi:I0.1038/npp.20I4.202; published online 24 September 2014

\section{INTRODUCTION}

It is well known that peripheral inflammatory factors influence central nervous system functioning, effects that contribute to behavioral correlates of systemic inflammation. Increasing evidence suggests these effects are bidirectional, whereby central mechanisms, including altered immunological, neural, and neuroendocrine activity modulate peripheral immune function, potentially creating positive feedback loops that influence risk or perpetuate

* Correspondence: Dr AR Prossin, Department of Psychiatry, University of Texas Health Science Center at Houston, 1941 East Road, Suite \#2308, Houston, TX 77054, USA, Tel: +734 389 9397, office: 7I 3 486 2836, E-mail: alan.prossin@uth.tmc.edu

Deceased

Received 20 February 2014; revised 2 June 2014; accepted 28 June 2014; accepted article preview online 20 August 2014 pathological states (Anisman et al, 1993; Dantzer et al, 2008). Pro-inflammatory cytokine elevations have been described in pathological states that include depressive illness (Miller et al, 2009), persistent pain states (Watkins et al, 1994; Hutchinson et al, 2008), and their comorbidity (Zautra et al, 2007). However, substantial inter-individual inflammatory variability has been noted across studies. For example, although individual studies in fibromyalgia (FM) identified elevations in certain peripheral inflammatory cytokines (eg, IL-1 receptor antagonist (IL-1ra), IL-6, IL-8) in FM volunteers (Salemi et al, 2003; Uceyler et al, 2006; Gur and Oktayoglu, 2008), meta-analyses did not show significance for many of these effects, likely reflecting heterogeneity in this syndromic presentation and methodological variation (Uceyler et al, 2011). Beyond variations in pathology, a fundamental question not yet addressed is how inflammatory variability impacts brain mechanisms associated with risk or resiliency for pathological states. 
The central endogenous opioid neurotransmitter system (including $\mu$-opioid receptors) is implicated in inflammatory-central nervous system interactions (Day and Akil, 1996; Peterson et al, 1998; Prossin et al, 2011), emotion dysregulation (Prossin et al, 2010), and chronic pain (Jones et al, 1994; Harris et al, 2007). Early in vitro evidence showed that interleukin-1 $\beta$ (IL-1 $\beta)$ reduced $\mu$-opioid receptor binding in brain membrane preparations (Ahmed et al, 1985) and acutely increased $\mu$-opioid receptor and pro-enkephalin mRNA expression in astrocyte-enriched cultures (Ruzicka and Akil, 1997). Peripheral IL-1 $\beta$ potently reduces opioid analgesia (Hutchinson et al, 2008) and facilitates morphine tolerance (Shavit et al, 2005), effects antagonized by IL-1 ra (Raghavendra et al, 2002; Shavit et al, 2005; Hutchinson et al, 2008). These opposing IL-1 $\beta$ and IL-1ra moderated effects are thought to take place through interactions with both non-classic opioid receptors on glial cells and traditional $\mu$-opioid receptors involved in endogenous opioid neurotransmission (Hutchinson et al, 2011).

In animal models, in vivo systemic administration of IL-1 $\beta$ has been shown to increase early gene (c-fos) expression in cells within the central nucleus of the amygdala and bed nucleus of the striae terminalis, two brain regions critical in regulating pain and stress responses (Day and Akil, 1996). Follow-up work showed the majority of these cells expressed primarily enkephalin, an endogenous ligand for $\mu$-opioid receptors. These findings suggest IL-1 $\beta$ effects are selective for endogenous opioid neurotransmitter systems, particularly within these brain regions (Day and Akil, 1999a; Day et al, 1999b). Interactions between IL-1 $\beta$ and central opioid neurotransmission have also been demonstrated through enhanced fos-immunoreactivity in the amygdala and bed nucleus of the striae terminalis in rats pre-treated with intra-arterial IL- $1 \beta$ and naloxone, an opioid receptor antagonist (Buller et al, 2005). $\mathrm{Mu}$-opioid-receptor-mediated neurotransmission in the amygdala and interconnected brain regions including the ventral basal ganglia, thalamus, and anterior cingulate cortex can regulate emotional states (Prossin et al, 2010), reward mechanisms and behavior associated with substance abuse (Ray et al, 2011), the pain experience (Zubieta et al, $2001,2002)$, the pathophysiology of persistent pain states (Jones et al, 1994; Harris et al, 2007), and sex differences in these phenomena (Zubieta et al, 2002).

In addition to immune to central effects, central neurotransmission also appears to influence innate immune responses to stress. Mu-opioid receptor agonists can regulate peripheral immune response, either directly or indirectly via modulation of both the hypothalamicpituitary-adrenal axis and the autonomic nervous system (Vallejo et al, 2004). Psychological stress challenges known to activate the hypothalamic-pituitary-adrenal axis have also been shown to increase plasma IL-1 $\beta$ concentrations (Yamakawa et al, 2009). Similar psychological stress challenges have been shown to induce plasma IL-1ra, an antagonist to IL-1 $\beta$, but with a temporal delay (Rohleder et al, 2006).

In the present study, we examined the relationship between peripheral cytokines, specifically IL-1 $\beta$ and IL-1ra, and central $\mu$-opioid receptor availability in healthy volunteers using molecular imaging techniques with PET and the selective $\mu$-opioid receptor radiotracer $\left[{ }^{11} \mathrm{C}\right]$ carfentanil. These effects were examined at baseline and during a psychophysical challenge with both emotionally and physically stressful components, moderate levels of deep muscular pain, known to activate endogenous, $\mu$-opioid-receptor-mediated neurotransmission (Zubieta et al, 2001). The potential effects of sex and neuroticism scores (NEO-PI, (Costa and McCrae, 1992), known to influence innate immune responses, risk for idiopathic pain syndromes and psychopathology (Angst and Clayton, 1986; Berkley et al, 2006), were also explored in these analyses. On the basis of animal data, it was hypothesized that in healthy controls, baseline plasma IL-1 family cytokines (including both IL-1 $\beta$ and IL-1ra) and their changes in response to the pain challenge would be linearly proportional to baseline $\mu$-opioid receptor availability and endogenous $\mu$-opioid receptor activation during the pain challenge, considering the contribution of other influencing factors (sex, neuroticism).

\section{MATERIALS AND METHODS}

\section{Subjects}

Participants included 34 healthy volunteers (22 female, 12 male) recruited through local advertising. Absence of current or past psychiatric diagnoses including substance abuse or dependence was confirmed with the Structured Clinical Interview for DSM-IV non-patient version (First and Spitzer 1995). All volunteers were right-handed, non-smokers without active medical illness and free from psychotropic medications, including sleep aids for the prior 6 months. Females had regular menstrual cycles (28-32 days) and were studied during their follicular phase (days 2-10 post menses), as determined by menstrual diaries and confirmed by plasma levels of estradiol and progesterone at the time of scanning. All volunteers had negative pregnancy and drug screens. All PET scans were conducted at the same time of day, with radiotracer administration at $13: 30 \mathrm{~h}$ to account for circadian variations. Calculated body mass index $\left(\mathrm{BMI}=\operatorname{weight}(\mathrm{kg}) / \mathrm{height}(\mathrm{m})^{2}\right)$ was normally distributed across our study population. Volunteers completed the NEO-PI; their scores were compared with median scores of comparable age population samples, using a median split to define relatively lower and higher neuroticism in between group statistical analyses.

The Institutional Review Board and the Radioactive Drug Research Committee approved the study. All subjects provided informed written consent at study entry.

\section{Experimental Pain Challenge}

We employed a physical and emotional stressor, moderate levels of sustained pain of experientially adjusted intensity as the challenge paradigm. In short, a steady state of moderate muscle pain was maintained $45-65 \mathrm{~min}$ after radiotracer administration via computer-controlled infusion of medication-grade hypertonic saline (5\%) into the relaxed left masseter muscle. The intensity of painful stimulus was standardized across subjects, as previously described (Zubieta et al, 2002). A non-painful control condition, $0.9 \%$ saline, was introduced in the right masseter muscle $5 \mathrm{~min}$ after radiotracer administration and also 
maintained for $20 \mathrm{~min}$. To avoid carry-over effects of the pain challenge, conditions were not randomized. Pain intensity was rated for both conditions every $15 \mathrm{~s}$ with a visual analogue scale (VAS) from 0 (no pain) to 100 (most intense pain imaginable) and were recorded in the computer controller and averaged for statistical analyses. The ratio of pain intensity to the infusion volume required for pain maintenance provided a measure of volunteer sensitivity to sustained pain (VAS/ml). Integrative measures of the pain experience were obtained using the McGill pain questionnaire (MPQ: Total, Sensory and Affective Pain scores) and VAS pain intensity scale, administered upon completion of the pain challenge (Melzack, 1975). The Positive and Negative Affect Schedule (Watson et al, 1988), assessing the internal affective state of the volunteers, was obtained before and after the challenge.

\section{Neuroimaging Measures}

One $\left[{ }^{11} \mathrm{C}\right]$ carfentanil PET scan per subject was acquired with a Siemens $\mathrm{HR}^{+}$scanner (Knoxville, TN) in 3-D mode (reconstructed FWHM resolution, $5.5 \mathrm{~mm}$ in-plane and $5.0 \mathrm{~mm}$ axially) over $90 \mathrm{~min}$, comprising baseline $(0-45 \mathrm{~min})$ and experimental pain challenge conditions (45-90 min). Radiotracer synthesis, image acquisition, co-registration, and reconstruction protocols were identical to those previously described (Zubieta et al, 2002). Image data were then transformed on a voxel-by-voxel basis into two sets of parametric maps, a tracer transport measure $\left(\mathrm{K}_{1}\right.$ ratio), and a receptor-related measure (non-displaceable binding potential, $\mathrm{BP}_{\mathrm{ND}}$, or receptor availability in vivo (Yasuno et al, 2007). To avoid the need for arterial blood sampling, these measures were calculated using a modified Logan graphical analysis (Logan et al, 1996), and the occipital cortex (an area devoid of $\mu$-opioid receptors) as reference region. Using a bolus-continuous radiotracer infusion, the slope of the Logan plot becomes linear 5-7 min post tracer administration and is proportional to the receptor concentration divided by its affinity for the radiotracer $\left(\mathrm{BP}_{\mathrm{ND}}+1\right.$, or $\left.\left(\mathrm{f}_{2} \mathrm{Bmax} / K_{\mathrm{d}}\right)+1\right)$. Bmax is the receptor concentration and $K_{\mathrm{d}}$, the receptor-ligand dissociation constant. The term $f_{2}$ refers to the concentration of free radiotracer in the extracellular fluid and is considered to represent a constant and very small value. Reductions in the in vivo availability of receptors, the $\mathrm{BP}_{\mathrm{ND}}$ measure, after the pain stress challenge are thought to reflect processes associated with neurotransmitter release, such as competition between radiotracer and endogenous ligand and changes in receptor affinity induced by endogenous ligand-receptor interactions, the latter relevant for agonist radiotracers, which preferentially label high affinity, functional receptors (Narendran and Martinez, 2008). Anatomical MRI studies were acquired on a 3-T scanner (General Electric, Milwaukee, WI). Acquisition sequences were axial spoiled gradient recall inverse recovery prepared magnetic resonance (echo time, $3.4 \mathrm{~ms}$; repetition time, $10.5 \mathrm{~ms}$; inversion time, $200 \mathrm{~ms}$; flip angle, $25^{\circ}$; number of excitations, 1 ; using 124 contiguous images, $1.5-\mathrm{mm}$ thickness). The $\mathrm{K}_{1}$ and $\mathrm{BP}_{\mathrm{ND}}$ images for each experimental period and the anatomical MRI were co-registered to each other and to the Montreal Neurological Institute (MNI) stereotactic atlas orientation (Meyer et al, 1997).

\section{Inflammatory Measures}

IL-1 $\beta$ and IL-1ra plasma levels were obtained after the control condition and pain challenge, 40 and $90 \mathrm{~min}$ after radiotracer administration, respectively. Plasma was aliquotted and stored at $-80^{\circ} \mathrm{C}$ until assayed. All plasma samples were run in duplicate using multiplex ELISA kits (Millipore, MA) with minimal detectable levels of $15 \mathrm{pg} / \mathrm{ml}$ (IL- $1 \beta$ ) and $30 \mathrm{pg} / \mathrm{ml}$ (IL-1ra). This was calculated by adding two standard deviations to the mean fluorescence index obtained when the zero standard was assayed 30 times. The highest standard was $12810 \mathrm{pg} / \mathrm{ml}$ for IL-1 $\beta$, and $30900 \mathrm{pg} / \mathrm{ml}$ for IL-1ra. Both IL-1 $\beta$ and IL-1ra were $\log _{10}$ normalized for statistical analyses.

\section{Data Analysis}

Analyses included baseline and pain challenge states. Using MANCOVA, we evaluated effects of factors of interest (sex, neuroticism) on inflammatory variables (IL-1 $\beta$ and IL-1ra) at baseline. Subsequently, using hierarchical, linear regression, we evaluated the contributions of categorical (sex, neuroticism) and continuous predictors (baseline IL-1 $\beta$, IL-1ra) to pain sensitivity (VAS/ml). Non-neuroimaging analyses involving inflammatory variables were not corrected for multiple comparisons.

Using repeated measures MANOVA, we evaluated effects of challenge condition (pain, control) on inflammatory variables (IL-1 $\beta$ and IL-1ra), and interactions with sex and neuroticism. Hierarchical, linear regression evaluated the contributions of categorical (sex, neuroticism) and continuous predictors (IL-1 $\beta$, IL-1ra) on measures of pain sensitivity during the pain challenge.

Using the general linear model in SPM8 (Wellcome Trust, London, England), we tested for the presence of linear relationships between baseline $\mu$-opioid receptor availability and inflammatory measures (eg, IL-1 $\beta$, IL-1ra) at baseline and following the pain challenge on a voxel-by-voxel basis with sex and neuroticism (low $v s$ high) as covariates. $t$-Statistic values were calculated with pooled variance across voxels (Worsley et al, 1995) with a statistical threshold of $p<0.001$ for the amygdala, an a priori hypothesized region). A threshold controlling for a type-I error rate at $p<0.05$ after correcting for focal extent was employed for all other regions (Friston et al, 1994).

Given IL-1 $\beta$ 's known hyperalgesic effects (Watkins et al, 1994; Shavit et al, 2005; Hutchinson et al, 2008), we hypothesized that variations in IL- $1 \beta$ levels during the pain stressor would moderate endogenous opioid system responses and their pain regulatory effects. Using the Process function in SPSS (Hayes, 2012), we explored the moderating effects of plasma IL-1 $\beta$ (moderator) following the pain challenge on the magnitude of $\mu$-opioid system activation (independent variable) with MPQ Pain Scores as the outcome variable, accounting for the contribution of BMI and baseline IL-1 cytokine concentrations.

\section{RESULTS}

Volunteer demographic and anthropometric data and baseline measures are shown in Table 1. No sex differences were observed for age, BMI, or neuroticism (two-tailed 
Table I Volunteer Demographic, Psychophysical, and Anthropometric Information and Baseline Measures

\begin{tabular}{|c|c|c|c|c|}
\hline \multirow{2}{*}{$\begin{array}{l}\text { Measures }(n=34) \\
\text { Females }=22 \\
\text { Males }=12\end{array}$} & \multicolumn{4}{|c|}{$\begin{array}{c}\text { Baseline } \\
(\text { Mean }+I-\text { SD) }\end{array}$} \\
\hline & $\begin{array}{c}\text { Total } \\
(n=34)\end{array}$ & $\begin{array}{c}\text { Females } \\
(n=22)\end{array}$ & $\begin{array}{c}\text { Males } \\
(n=12)\end{array}$ & T-Test \\
\hline Age (years) & $22 \pm 11$ & $21 \pm 13$ & $24 \pm 8$ & $T=-0.8 ; p=0.4$ \\
\hline Body Mass Index $\left(\mathrm{Kg} / \mathrm{m}^{2}\right)$ & $25 \pm 4$ & $24 \pm 4$ & $26 \pm 4$ & $T=-1.3 ; p=0.2$ \\
\hline \multicolumn{5}{|l|}{ Females $(n=22)$} \\
\hline Cycle Day & \multicolumn{4}{|c|}{$8 \pm 6$ days } \\
\hline Testosterone & \multicolumn{4}{|c|}{$56 \pm 21 \mathrm{ng} / \mathrm{dl}$} \\
\hline Estrogen & \multicolumn{4}{|c|}{$104 \pm 74 \mathrm{pg} / \mathrm{ml}$} \\
\hline Progesterone & \multicolumn{4}{|c|}{$3 \pm 5 \mathrm{ng} / \mathrm{ml}$} \\
\hline
\end{tabular}

Table I provides demographic, psychophysical, and anthropometric information on our study volunteers. Measures of age, weight, height, and NEO PI-R were obtained at study entry for all volunteers. Body Mass Index (BMI) was calculated using the ratio (weight in $\mathrm{kg}$ )/(height in $\mathrm{m}^{2}$ ). $\mathrm{N}$-Factor scores were calculated as described in the NEO PI-R manual. Results for all measures are reported as mean + / - standard deviation. Independent sample T-testing showed that no significant sex difference was found with regards to either age, BMI, or NEO-PI neuroticism ( $p>0.05$ for each). Also described in the table are sex hormone levels for all study volunteers.

$t$-tests, $p>0.05)$. Psychophysical and inflammatory data during control and pain challenges are described in Table 2.

\section{Baseline Measures: Effects of Sex and Neuroticism on Baseline IL-1 $\beta$ and IL-1ra}

At baseline, females showed higher IL- $1 \beta \quad\left(\mathrm{F}_{1,30}=32.2\right.$, $p<0.001)$ and IL-1ra $\left(\mathrm{F}_{1,30}=14.4, p=0.001\right)$ concentration compared with males (Figure 1a). Volunteers with high neuroticism had lower baseline IL- $1 \beta\left(\mathrm{F}_{1,30}=6.1, p=0.02\right)$ than those with low neuroticism, but effects of neuroticism on baseline IL-1ra were not significant $\left(\mathrm{F}_{1,30}=2.5, p=0.13\right)$ (Figure 1b). Significant sex by neuroticism interactions were noted for baseline IL-1 $\beta \quad\left(\mathrm{F}_{1,30}=6.1, p=0.02\right)$, but not IL-1ra $\left(\mathrm{F}_{1,30}=1.2, p=0.28\right)$. Low neuroticism scores were associated with greater baseline plasma IL-1 $\beta$ in females, but not in males (Figure 1c).

\section{Baseline Measures: Relationships between IL-1 Family Cytokines at Baseline and Pain Sensitivity}

Results from hierarchical linear regression were: Step 1: Without considering effects of sex and neuroticism, the model significantly predicted pain sensitivity (VAS/ml) with $\Delta \mathrm{R}^{2}=0.26, \Delta \mathrm{F}_{2,31}=5.4, p=0.01$ and acceptable collinearity (Tolerance $=0.4 ; \mathrm{VIF}=2.7)$. Both baseline IL-1 $\beta(\beta=0.62$, $\mathrm{T}=2.5, \quad p=0.02)$ and IL-1ra $(\beta=-0.83, \mathrm{~T}=-3.3$, $p=0.003)$ were associated with sustained pain sensitivity during the challenge, but with opposing effects (ie, higher concentration of IL- $1 \beta$ was associated with greater pain sensitivity; higher concentration of IL-1ra was associated with less pain sensitivity). Sex and neuroticism were included in Step 2: IL- $1 \beta(\beta=0.62, \mathrm{~T}=2.2, p=0.01)$ and IL-1ra $(\beta=-0.83, \mathrm{~T}=-3.2, \quad p=0.004)$ predicted pain sensitivity, but sex and neuroticism did not have a significant effect on this model ( $p>0.10$ for each).

Baseline Measures: Relationships between IL-1 $\beta$, IL-1ra, and Baseline $\mu$-Opioid Receptor Availability

IL-1 $\beta$ was negatively associated with baseline $\mu$-opioid receptor $\mathrm{BP}_{\mathrm{ND}}$ exclusively in the amygdala bilaterally (Right: $\mathrm{Z}_{25}=-4.7, p<0.001, \mathrm{r}=-0.44$ for extracted data; Left: $\mathrm{Z}_{25}=-4.8, \quad p<0.001, \quad \mathrm{r}=-0.36$ for extracted data) (Table 3, Figure 2a). No associations were identified between baseline IL-1ra and $\mu$-opioid receptor availability. Pain sensitivity correlated with baseline $\mu$-opioid receptor availability bilaterally at trend, non-statistically significant levels (Right: $\mathrm{r}=-0.29, p=0.08$; Left: $\mathrm{r}=-0.29, p=0.09$ ).

\section{Sustained Pain Challenge: Effects of Sex and Neuroticism on Changes in IL-1 $\beta$ and IL-1ra During the Pain Stressor}

Overall, the pain challenge had a nearly significant effect on IL-1 $\beta$ plasma levels $\left(\mathrm{F}_{1,30}=3.7, p=0.06\right.$; mean $\log _{10}$ IL- $1 \beta$ reduction, 0.15$)$, but not on IL-1ra $(\mathrm{p}>0.10)$. Interactions between challenge condition (pain/control) and sex had nearly significant effects on IL- $1 \beta\left(\mathrm{F}_{1,30}=3.7, p=0.06\right)$ but not on IL-1ra $(p>0.10)$. Pain induced an IL-1 $\beta$ increase in females (mean $\log _{10}$ IL-1 $\beta$ increase of 0.30 ) but no noticeable IL- $1 \beta$ changes (mean $\log _{10}$ IL- $1 \beta$ increase of 0.002 ) in males (Figure 3a). Significant effects of neuroticism on pain associated cytokine changes were observed for IL-1 $\beta\left(\mathrm{F}_{1,30}=9.6, p=0.004\right)$ but not IL-1 ra $(p>0.10)$. Pain induced an increase in IL-1 $\beta$ (mean $\log _{10}$ IL- $1 \beta$ increase of 0.10 ) in volunteers with high neuroticism and an IL-1 $\beta$ reduction (mean $\log _{10}$ IL-1 $\beta$ reduction of 0.40 ) in those with low neuroticism (Figure $3 \mathrm{~b}$ ). Three-way interactions 
Table 2 Psychophysical and Inflammatory Response to Pain

\begin{tabular}{|c|c|c|c|}
\hline $\begin{array}{l}\text { Measures }(n=34) \\
\text { Females }=22 \\
\text { Males }=12\end{array}$ & $\begin{array}{l}\text { Control condition } \\
(\text { Mean }+I-S D)\end{array}$ & $\begin{array}{l}\text { Following pain challenge } \\
\quad(\text { Mean }+I-\text { SD) }\end{array}$ & Paired t-test \\
\hline IL-Ira $\left(\log _{10}\right)$ & $2.1 \pm 0.5$ & $2.2 \pm 0.6$ & $T=0.8 ; p=0.40$ \\
\hline Negative Affect (PANAS) & $2.3 \pm 2.8$ & $2.4 \pm 4.8$ & $T=0.1 ; p=0.91$ \\
\hline Positive Affect (PANAS) & $9.1 \pm 6.5$ & $9.4 \pm 5.6$ & $T=0.6 ; p=0.55$ \\
\hline
\end{tabular}

Measures $(n=34)$

Results from Pain Challenge

(Mean $+I-$ SD)

VAS Average (0-20 min)

$28 \pm 13$

Volume Infused (ml)

$2.9 \pm 1.2$

(VAS Average)/(Volume Infused)

$1.5 \pm 1.2$

Pain Intensity (VAS)

$40 \pm 14$

MPQ Sensory $(1-10)$

$15 \pm 7$

MPQ Affect $(11-16+20)$

$5.3 \pm 4.7$

MPQ Total ( $1-20)$

$24 \pm 12$

Table 2 provides information regarding measures assessed during the study and includes data obtained on IL-I family cytokines, measures of affective state (PANAS; both Positive and Negative Affect scores), as well as measures of both pain sensitivity (VAS average/volume of pain stimuli infused) and the pain experience (eg, MPQ Sensory, Affect, and Total Pain scores). Cytokine concentrations are reported in their Log 10 normalized format. Raw cytokine concentrations were detected via standard ELISA techniques in units of pg/dl. Independent sample T-testing showed that when looking at the entire study sample, without accounting for factors associated with inflammatory and pain variance, the pain challenge did not induce a significant change in either our IL-I family cytokines measures or our measures of affective state (eg, PANAS). The McGill Pain Questionnaire (MPQ) was obtained following the pain induction. Results for all measures are reported as mean $+/$ - standard deviation.

between neuroticism, sex, and challenge condition (pain/ control) were observed for IL-1 $\beta\left(\mathrm{F}_{1,30}=9.5, p=0.004\right)$ but not IL-1ra $(p>0.05)$. No change in IL- $1 \beta$ was observed in males (irrespective of neuroticism group), but pain induced an increase in IL- $1 \beta$ (mean $\log _{10}$ IL- $1 \beta$ increase of 0.19 ) in females with higher neuroticism, and induced a reduction in IL-1 $\beta$ (mean $\log _{10}$ IL-1 $\beta$ reduction of 0.80 ) in females with lower neuroticism (Figure $3 c$ ).

\section{Sustained Pain Challenge: Relationships between IL-1 Family Cytokines During the Pain Challenge and Pain Sensitivity}

Results from the hierarchical linear regression were: Step 1: Without considering sex and neuroticism, the model was significant with $\Delta \mathrm{R}^{2}=0.19, \Delta \mathrm{F}_{2,31}=3.7, p=0.04$ and acceptable collinearity (Tolerance $=0.5 ; \mathrm{VIF}=1.8$ ). The impact of pain on both IL- $1 \beta(\beta=-0.56, \mathrm{~T}=-12.6$, $p=0.01)$ and IL-1ra $(\beta=0.52, \mathrm{~T}=2.4, p=0.02)$ significantly predicted pain sensitivity, but with opposing effects for IL-1 $\beta$ and IL-1ra. Including sex and neuroticism in the model in Step 2 rendered the model non-significant $\left(\Delta \mathrm{R}^{2}<0.01, \Delta \mathrm{F}_{2,29}<0.01, p=0.99\right.$

Sustained Pain Challenge: Relationships between IL-1 $\beta$, IL-1ra, and Pain-induced $\mu$-Opioid System Activation

No significant relationships between endogenous opioid system activation (measured as reductions in $\mathrm{BP}_{\mathrm{ND}}$ during the challenge, compared to the control condition) and changes in IL-1 $\beta$ concentrations were observed. Conversely, challenge-induced changes in IL-1ra were associated with $\mu$-opioid system activation bilaterally in the dorsomedial nucleus accumbens/ventral caudate (Right: $Z_{25}=5.5$, $p<0.001$; Left: $Z_{25}=5.4, p<0.001$ ) (Table 3, Figure 2b).

\section{Moderating Effects of Pain-induced Changes in IL-1 $\beta$ on Endogenous Opioid Analgesia following the Pain Challenge}

Results from moderation analyses showed that changes in IL-1 $\beta$ associated with the pain challenge moderated the relationship between challenge-induced endogenous opioid system activation in the left dorsomedial nucleus accumbens/ventral caudate region and the subjective experience of pain as measured by MPQ Pain Sensory, and MPQ pain Affect scores following the pain challenge (Figure 4). Model 1: the model was significant $\left(\Delta \mathrm{R}^{2}=0.23, \mathrm{~F}_{6,26}=2.8\right.$, $p=0.03$ ), whereby pain induced changes in IL- $1 \beta$ moderated the relationship between endogenous opioid system activation in the dorsomedial nucleus accumbens/ventral caudate and reductions in MPQ Sensory scores $(B=-36.3$, $\mathrm{T}=-3.6, p=0.001$ ) (Figure 4a). Model 2: the model was significant $\left(\Delta \mathrm{R}^{2}=0.20, \mathrm{~F}_{6,26}=5.8, p<0.001\right)$ whereby painassociated changes in IL-1 $\beta$ moderated the relationship between endogenous opioid system activation in the dorsomedial nucleus accumbens/ventral caudate and reductions in MPQ Affect scores $(B=-18.2, T=-5.0$, $p<0.0001$ ) (Figure $4 \mathrm{~b}$ ). Two additional models were tested to determine the moderating effect of $\mathrm{IL}-1 \beta$ on the 
175

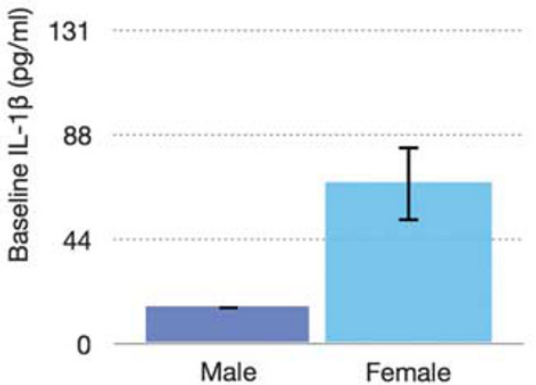

b

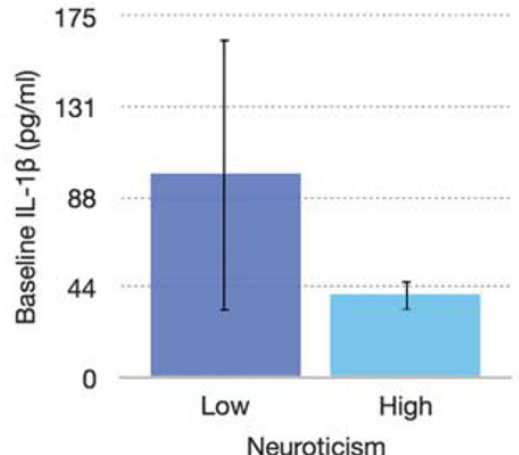

C
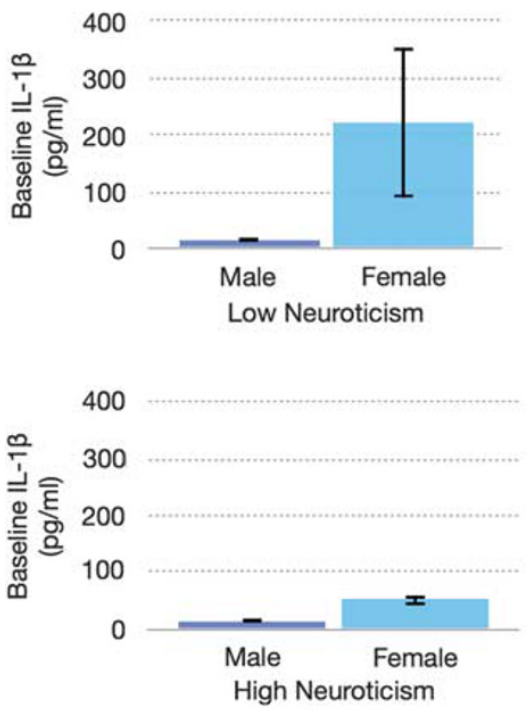

650
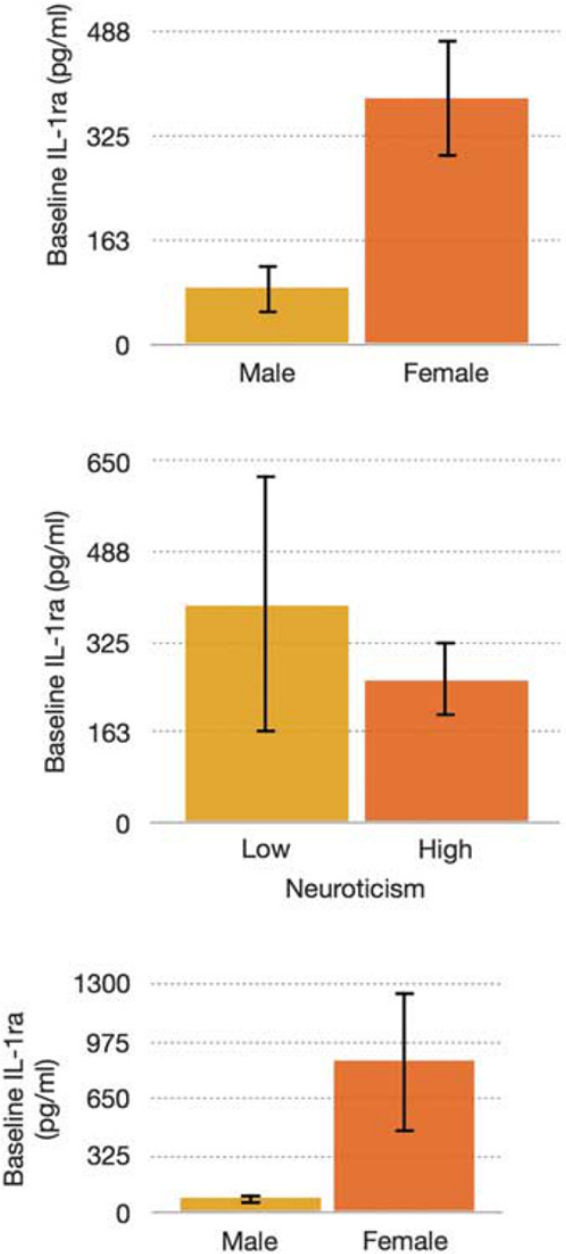

Low Neuroticism

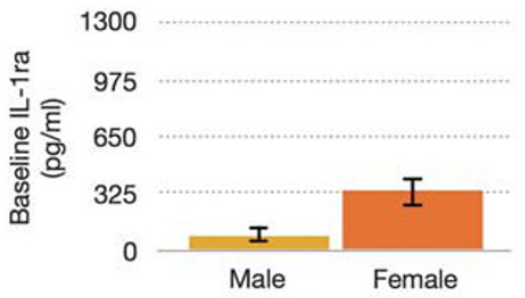

High Neuroticism

Figure I Impact of sex and neuroticism on baseline plasma IL-I $\beta$ and IL-I ra. Many factors are believed to be associated with variability in plasma concentration of inflammatory cytokines. Here, we present graphical comparisons of plasma concentration of IL-I $\beta$ (depicted here in blue) and IL-I ra (depicted here in Maize) across two biobehavioral factors, sex, and neuroticism. For clarity in presentation, here we present the raw cytokine concentrations. (a) Graphs here illustrate the effect of sex (eg, male vs female) (X-axes) on baseline plasma IL-I $\beta$ (depicted here in blue) and IL-I ra (depicted here in Maize) (Y-axes) in our sample. (b) Graphs here illustrate the effect of neuroticism (eg, lower: <mean - ISD; higher: > mean - ISD) (X-axes) on baseline plasma ILI $\beta$ (depicted here in blue) and IL-I ra (depicted here in Maize) (Y-axes) in our sample. (c) Graphs here illustrate the sex by neuroticism interaction effect on baseline plasma IL-I $\beta$ (depicted here in blue) and IL-I ra (depicted here in Maize) (Y-axes) in our sample. Sex is shown on the X-axes and neuroticism is depicted on the right side of the graphs. Significant sex by neuroticism interaction effects on IL-I $\beta$ were detected in our sample. The sex by neuroticism interaction significantly impacted baseline IL-I ra.

relationship between endogenous opioid system activation in the right dorsomedial nucleus accumbens/ventral caudate and the extent of pain experienced. One of these models related to MPQ sensory pain and one model related to MPQ affective pain. The results from each of these additional analyses were found non-significant $(p>0.05)$. 
Table 3 Pain-induced Changes in Peripheral IL-I $\beta$ and IL-I ra is Associated with Concurrent Pain-induced Central Regional $\mu$-Opioid Receptor Activation

\begin{tabular}{|c|c|c|c|}
\hline Cytokine & Brain Regional $\mu$-OR BP ND & MNI Coordinates $(x, y, z)$ & Statistics \\
\hline \multicolumn{4}{|l|}{ Control Condition } \\
\hline$|\mathrm{L}-| \beta$ & $\begin{array}{l}\text { Right Amygdala } \\
\text { Left Amygdala }\end{array}$ & $\begin{array}{l}-24,-2,-21 \\
21,-1,-23\end{array}$ & $\begin{array}{l}\text { Size }=319 ; Z_{25}=-4.7, p<0.001 \\
\text { Size }=429 ; Z_{25}=-4.8, p<0.001\end{array}$ \\
\hline IL-Ira & None & None & None \\
\hline \multicolumn{4}{|c|}{ Response to Pain Challenge } \\
\hline$|\mathrm{L}-| \beta$ & None & None & None \\
\hline IL-Ira & $\begin{array}{l}\text { Right VP/NAcc } \\
\text { Left VP/NAcc }\end{array}$ & $\begin{array}{l}-12,13,1 \\
7,9-1\end{array}$ & $\begin{array}{l}\text { Size }=579 ; Z_{25}=5.5, p<0.001 \\
\text { Size }=844 ; Z_{25}=5.4, p<0.001\end{array}$ \\
\hline
\end{tabular}

Table 3 outlines the results of correlational analyses between IL-I family cytokines and measures of $\mu$-opioid receptor (MOR) availability (and pain-induced MOR activation). MOR availability is reported in units of $\mathrm{BP}_{\mathrm{ND}}$ (eg, non-displaceable binding potential at central $\mu$-opioid receptors). Pain-induced $\mu$-opioid receptor activation is defined as the pain-induced reduction in BP $\mathrm{ND}$. MNI: Montreal Neurological institute. Here, we identify brain regions by name, associated MNI coordinates, as well as the size and statistics of the brain regions where MOR measures correlate with measures of peripheral IL-I family cytokines.

\section{DISCUSSION}

This study examined IL-1 $\beta$ and IL-1ra plasma levels at baseline and during a sustained pain challenge, the latter a model of physical and emotional stress, including sex and neuroticism as potential covariates, and their relationship with functional measures of a neurotransmitter system, the endogenous opioid and $\mu$-opioid receptors, involved in pain and stress regulation (Zubieta et al, 2002), known to be influenced by peripheral inflammatory changes in animal models (Day and Akil, 1999a). We observed significant relationships between peripheral IL-1 family cytokines and baseline $\mu$-opioid receptor availability in vivo, as well as pain-activated central endogenous opioid neurotransmission, one of the principal anti-nociceptive mechanisms, and which is implicated both in regulating the pain experience and stress responses (Zubieta et al, 2001) and sex differences in these phenomena (Zubieta et al, 2002).

At baseline, female sex was associated with higher plasma concentrations of IL-1 $\beta$ and IL-1ra, whereas neuroticism was linked to lower levels of IL-1 $\beta$. These inflammatory relationships with both female sex and neuroticism, factors generally attributed to increased risk for stress-induced emotional reactivity, negative affective states (Renner et al, 2013), and higher pain sensitivity (Pauli et al, 1999), suggest that activation of inflammatory pathways involving IL-1 family cytokines may contribute to biological risk for such pathologies. Further, lower $\mu$-opioid receptor availability has been associated with higher clinical pain in FM (Harris et al, 2007) and with elevated cortisol, ACTH, and treatment refractoriness in Major Depression (Kennedy et al, 2006). In our data, higher plasma IL- $1 \beta$ was associated with lower $\mu$ opioid receptor availability in the amygdala, a region where $\mu$-opioid receptors are implicated in the regulation of pain (Zubieta et al, 2002) and affective states (Liberzon et al, 2002; Prossin et al, 2011). Day and colleagues(Day et al, $1999 \mathrm{~b})$ reported similar findings in animal models wherein peripheral IL-1 $\beta$ administration selectively increased enkephalin expression and activated enkephalinergic cells within the central nucleus of the amygdala. Additional work also suggests that activation of extracellular signal-regulated kinases within the central nucleus of the amygdala can also modulate peripheral, inflammatory pain through descending pathways (Neugebauer et al, 2004; Carrasquillo and Gereau, 2007) suggesting a potential mechanism for bi-directional relationships between central systems and peripheral inflammatory responses. Additionally, contrary to IL-1 $\beta$, IL-1ra can penetrate the blood brain barrier (Cawthorne et al, 2011), and therefore the IL-1 $\beta$-central opioid relationships observed could also be modulated by IL-1ra, a potential effect that could be explored with larger sample sizes. Exactly why lower $\mu$-opioid receptor availability in the amygdala was only marginally associated with pain sensitivity is unclear. However, our findings from the pain challenge imply that pain sensitivity early in the pain challenge is more dependent on the extent of concurrent activation of central $\mu$-opioid receptors in response to pain rather than baseline endogenous $\mu$-opioid receptor availability. Findings in chronic pain patients are expectedly different, with lower baseline endogenous $\mu$-opioid receptor availability (within specific brain regions involved in regulating response to pain). In these individuals, the chronicity of pain likely serves to reduce central $\mu$-opioid receptor availability through either increased baseline endogenous opioid tone, or $\mu$-opioid receptor downregulation, both reducing effective analgesic capacity through their regionally specific effects.

During the pain stressor, an interaction between female sex and neuroticism was observed, whereby increases in IL-1 $\beta$ were observed in females in the high neuroticism group, but reductions in the female low neuroticism sample. In the neuroimaging data, activation of $\mu$-opioid receptor mediated neurotransmission by the pain stressor was positively associated with plasma IL-1ra, but not IL- $1 \beta$ in the dorsomedial nucleus accumbens, a brain region implicated in hedonic, social, and affiliative behavior (Resendez et al, 2013). The inflammatory sex differences identified are consistent with previous findings in animal 
a

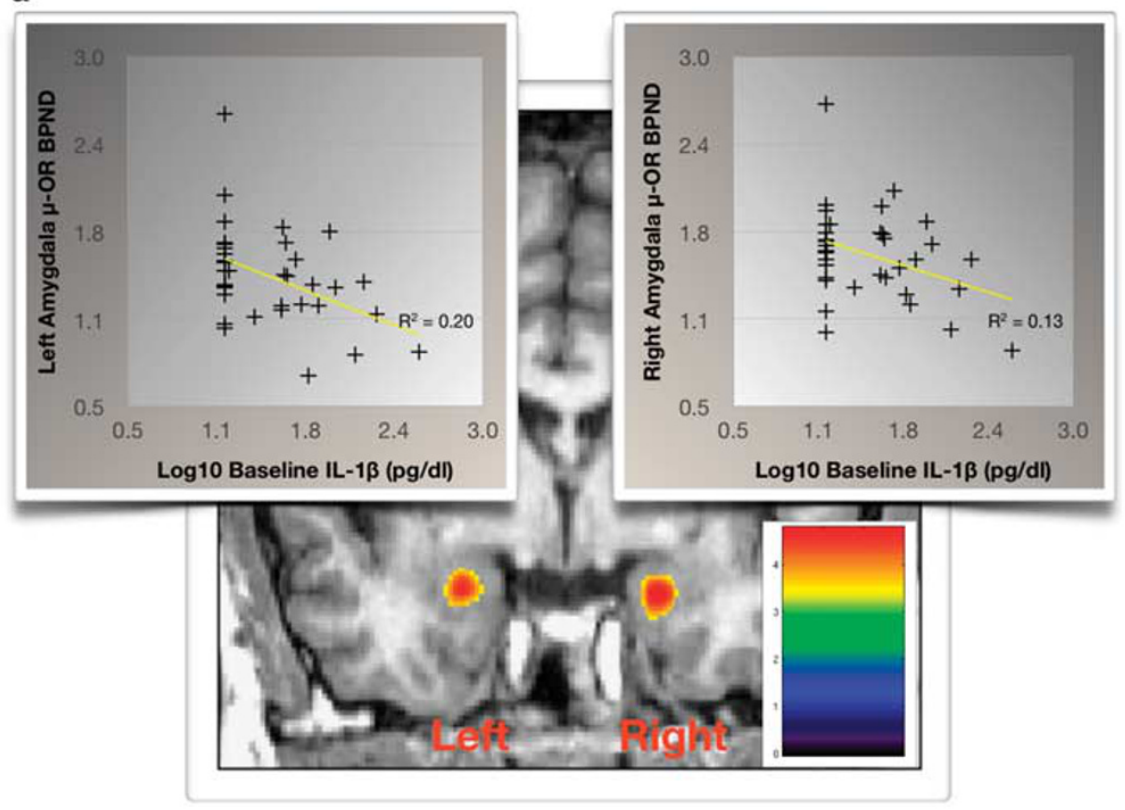

b

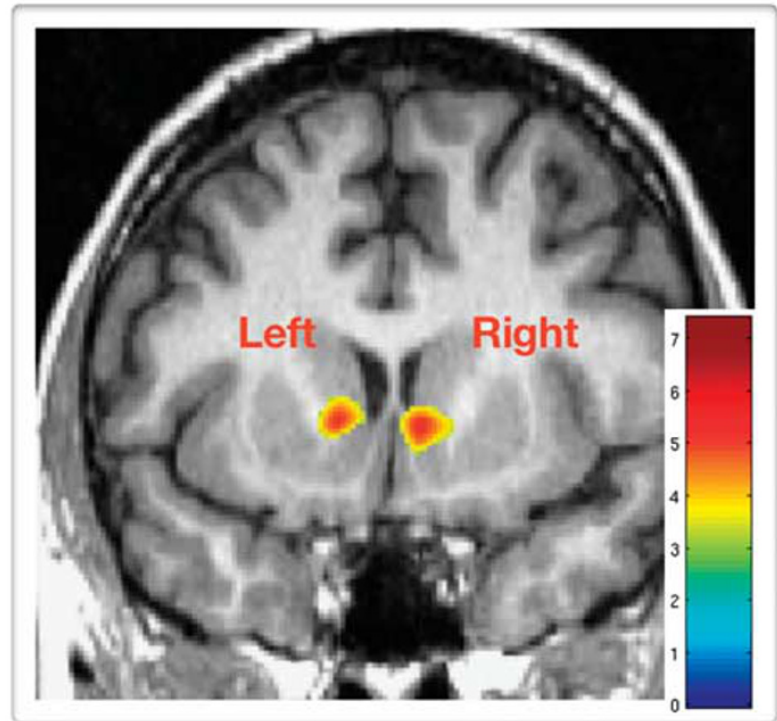

Figure 2 Correlations between concentrations of plasma IL-I family cytokines and measures of central $\mu$-opioid neurotransmission during a pain challenge. Z scores of statistical significance are represented by a pseudo color scale (inset) and are superimposed over an anatomically standardized magnetic resonance image in a coronal view. Image data are displayed according to standard radiological convention so that the left side of the image corresponds to the right side of the brain. (a) Shows the relationship between amygdala $\mu$-opioid receptor availability at baseline and plasma IL-I $\beta$, on a voxel-by-voxel basis and on the extracted data from those regions (Right: $r=-0.44, p=0.004$; Left: $r=-0.36, p=0.0$ I5). (b) Shows significant linear relationships between pain-induced activation of $\mu$-opioid neurotransmission and plasma IL-I ra concentrations in the dorsomedial NAcc/Ventral caudate (Right: $Z_{25}=5.5, p<0.00$ I; Left: $Z_{25}=5.4, p<0.00$ I).

models where sex differences in immune functioning have been reported (see review by Berkley and Zalcman) (Berkley et al, 2006). Here, we show that the pain challenge increased IL-1 $\beta$ but not IL-1ra (ie, increase in IL-1ra not statistically significant) in females. In the low neuroticism group, we observed higher IL- $1 \beta$ at baseline and a reduction in IL- $1 \beta$ following the sustained pain challenge. In contrast, high neuroticism, a trait often associated with risk for stressinduced pathological states, including idiopathic forms of pain (Angst and Clayton, 1986; Pauli et al, 1999; Zubieta et al, 2002; Paine et al, 2009; Vassend et al, 2013), was associated with lower baseline IL-1 $\beta$ but sustained pain-induced increases in that proinflammatory cytokine. Both sex and neuroticism accounted for substantial inter-individual inflammatory heterogeneity within healthy volunteers both at baseline and following the sustained pain stressor.

Isolated elevations in IL- $1 \beta$, in relation to IL-1 ra have been shown in animal models to precipitate a state of hyperalgesia (Raghavendra et al, 2002; Shavit et al, 2005). Here, we identified negative linear relationships between 
a

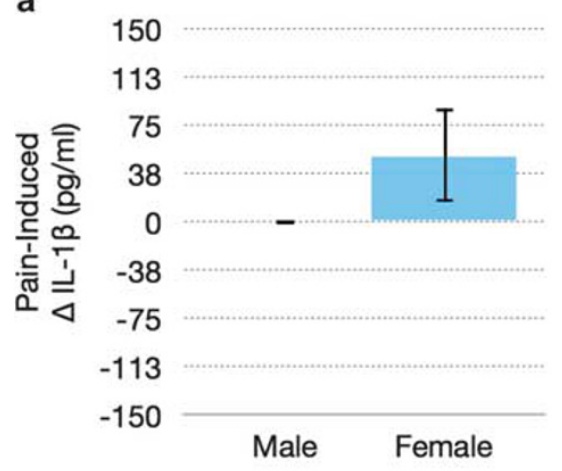

b

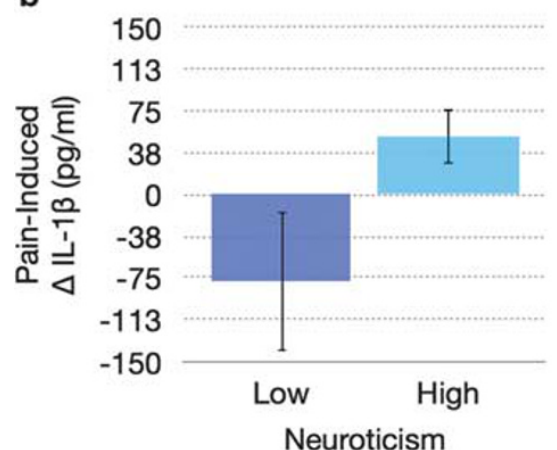

C
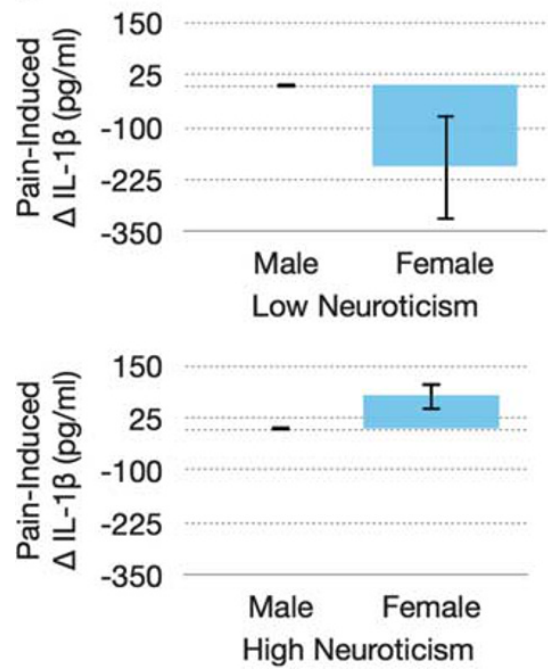
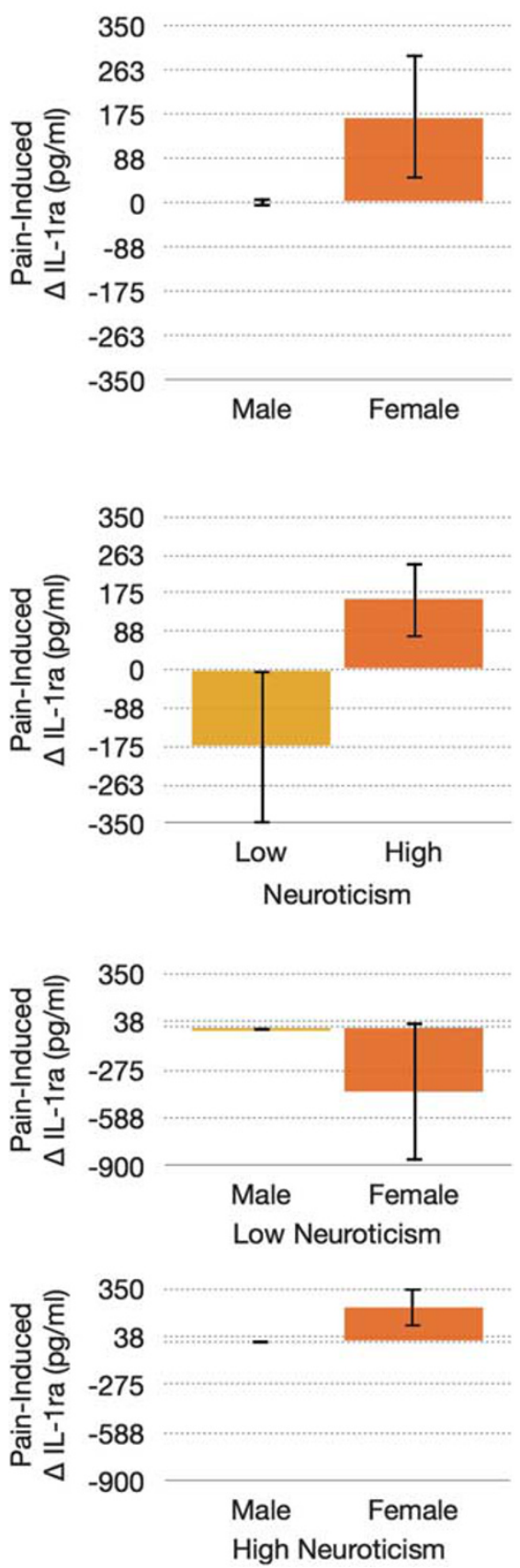

Figure 3 Impact of neuroticism and sex on pain induction of plasma IL-I $\beta$ and IL-I ra. Many bio-behavioral factors are believed to be associated with variability in the pain experience. Here, we provide graphical illustrations of two such factors (eg, sex, neuroticism) and their impact on pain-induced changes in plasma concentration of two inflammatory cytokines, IL-I $\beta$ and IL-I ra, implicated for their involvement in the pain experience. The Y-axes of the graphs represent the pain-induced change in cytokine concentrations; IL-I $\beta$ (blue bar graphs) and IL-I ra (maize bar graphs). Positive values represent a pain-induced increase (and negative values a pain-induced decrease) in the particular cytokine concentration. The effect of sex is depicted in (a), the effect of neuroticism is depicted in (b), and their interaction (eg, sex by neuroticism) is depicted with sex on the X-axes and neuroticism on the right-side axes in (c). (a) Here, we illustrate the effect of sex (X-axes) on both the pain-induced change in IL-I $\beta$ (Y-axis, blue bars) and the pain-induced change in IL-I ra (Y-axis, maize bars). (b) Here, we illustrate the effect of neuroticism (X-axes) on both the pain-induced change in IL-I $\beta$ (Y-axis, blue bars) and the pain-induced change in IL-I ra ( $Y$-axis, maize bars). (c) Graphs here illustrate the sex by neuroticism interaction effect on both the pain-induced change in IL-I $\beta$ (Y-axis, blue bars) and the pain-induced change in IL-Ira (Y-axis, maize bars). Sex is shown on the $\mathrm{X}$-axes and neuroticism is depicted on the right side of the graphs.

IL-1 $\beta$ and $\mu$-opioid receptor availability, hence reducing the functional capacity of this endogenous anti-nociceptive mechanism. Baseline IL-1 $\beta$ may therefore represent a marker of risk for the development of persistent pain states and other stress-associated pathologies, reducing $\mu$-opioid receptor availability and therefore the capacity to engage this neurotransmitter system to regulate pain and other forms of stress. 
a

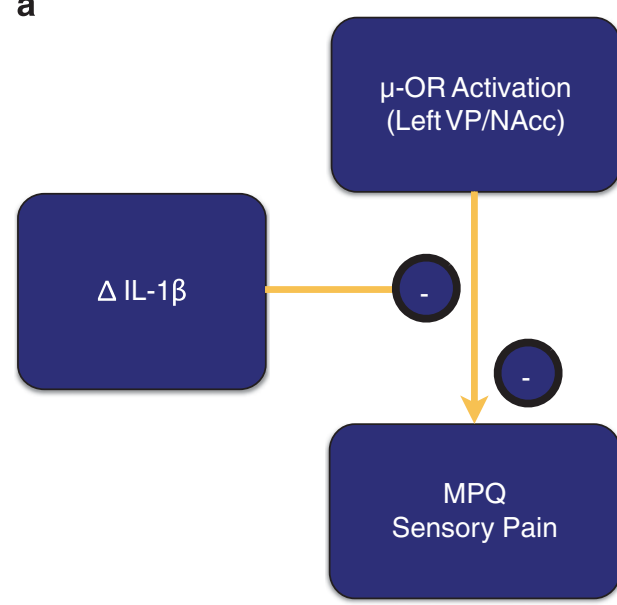

b

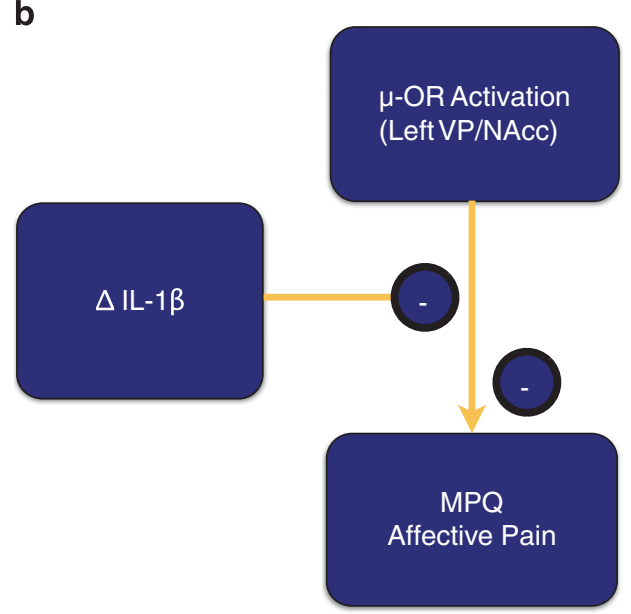

Figure 4 Moderating effect of the pain induced change in $I L-\mid \beta$ on the relationship between endogenous opioid activation in the left dorsomedial nucleus accumbens/ventral caudate and the extent of pain experienced in healthy volunteers during a standardized pain challenge. Two models are represented in this figure, one depicting $\Delta \mathrm{LL}-\mathrm{I} \beta$ moderating effects on endogenous opioid activation in the left dorsomedial nucleus accumbens/ ventral caudate where MPQ Sensory Pain score is the outcome (a) and another where MPQ Affective Pain score is the outcome variable (b). Two additional models were tested to determine the moderating effect of $\Delta \mathrm{IL}-$ I $\beta$ on the relationship between endogenous opioid activation in the right dorsomedial nucleus accumbens/ventral caudate and the extent of pain experienced, one model with MPQ sensory pain as the dependent and one model with MPQ affective pain as the dependent variable. The results from each of these additional analyses were found non-significant $(p>0.05)$ and are not represented in the figures.

We did not observe significant effects of the sustained pain challenge on IL-1ra plasma levels. However, temporal delays in stress-induced changes of IL-1ra have previously been reported that may account for this lack of findings. In one such study, Rohleder and colleagues (Rohleder et al, 2006) observed a 60-min delay following induction of psychosocial stress before significant stress-induced elevation in plasma IL-1ra was detected. Sampling of IL-1ra at periods longer than the $45 \mathrm{~min}$ employed in this study may therefore help to clarify the effects of IL-1ra on pain measures and of the effects of the pain challenge on IL-1ra.
However, such changes to the research paradigm would likely require an extension of the study time from $90 \mathrm{~min}$ to at least $120 \mathrm{~min}$, posing other limitations related to the decay of short-lived radiotracers $\left({ }^{11} \mathrm{C}\right.$ half-life $\left.=20 \mathrm{~min}\right)$, or the use of two separate radiotracer administrations. In spite of these potential limitations, IL-1ra, with its IL-1 $\beta$ antagonizing capacity, was found associated with greater pain-induced endogenous opioid system responses in the dorsomedial nucleus accumbens, potentially reducing the impact of the stressor on hedonic and motivational functions modulated by this brain region.

Endogenous opioid neurotransmission has been previously been shown to integrate systemic IL-1 $\beta$ input to the CNS (central amygdala) (Day et al, 1999b), modulate CNS outflow to the peripheral immune system in response to stressful events (amygdala, hypothalamus) (Buller et al, 2005), and regulate behavioral expectation and reward in anticipation of future events (nucleus accumbens) (Zubieta and Stohler, 2009), as well as regulating emotional responses to pain and other stressors (Zubieta et al, 2002; Prossin et al, 2011), as part of ascending pain-responsive pathways (Gear and Levine, 1995). The opposing effects of IL-1 $\beta$ (associated here with lower baseline receptor availability) and IL-1ra (associated with increases in endogenous opioid release) are potentially consistent with animal models of IL-1ra-induced analgesia, opposing the hyperalgesic effect of IL-1 $\beta$ (Raghavendra et al, 2002; Shavit et al, 2005). The observed linear relationships between measures of regional $\mu$-opioid receptor mediated neurotransmission and peripheral IL-1 $\beta$ (and IL-1ra), localized to brain regions in the mesolimbic reward and saliency response pathways could then be interpreted as participating in homeostatic responses to peripheral nociceptive stress as previously suggested in animal models (Gear and Levine, 1995; Gear et al, 1999). That IL- $1 \beta$ moderates the antinociceptive $\mu$-opioid receptor activation in the dorsomedial nucleus accumbens, an area in which endogenous opioid system activation was proportional to IL-1ra, increasing sensory and affective pain report in our data, also provides preliminary evidence to explain the role of these interdependent neuroimmune interactions in the host response to pain stress. That this effect was lateralized to the left, the same side as the algesic stimulus, may implicate the modulatory sensory matrix, previously reported to lateralize to the side of the nociceptive challenge as opposed to contra-lateral thalamic projections (Goadsby, 2005).

The data reported in the present manuscript translate initial observations of IL-1 family cytokine-central opioid interactions in animal models into human samples. Both IL-1 $\beta$ and IL-1ra appear associated with the function of endogenous opioid antinociceptive and stress regulatory mechanisms and to a lesser extent with sustained pain sensitivity measures. Stress-induced elevation in IL-1 $\beta$ levels, by moderating pain-induced $\mu$-opioid receptor activation in the nucleus accumbens, may represent a marker of vulnerability to persistent pain states. On the contrary, IL1-ra was associated with more efficient activation of potentially homeostatic endogenous opioid neurotransmission in the nucleus accumbens, regulating both responses to pain and motivational mechanisms. Future work in this area should consider the modulation of inflammatory cytokines as a potential mechanism to regulate 
dysfunctional central neurotransmission in pathological states, opening new therapeutic avenues for a number of disease processes, such as idiopathic pain syndromes, mood and substance use disorders, where endogenous opioid neurotransmission is implicated.

\section{FUNDING AND DISCLOSURE}

Dr Koch has recently been employed by Eli Lilly companies and has consulted for Metastatix, Pennside Partners, Cypress Bioscience, Takeda Pharmaceuticals, NiCox SA, Celtaxsys, Gerson Lehrman Group of Healthcare and Biomedical Advisors, Guidepoint Global, UCB Pharmaceuticals, and the Fund for Autoimmune Research and has been an expert for Kirkland and Ellis. Dr Koch has received investigator-initiated research grants for Bristol-Myers Squibb, Roche, and Takeda Pharmaceuticals. All other authors report no biomedical financial or potential conflicts of interest. K99 DA 033454 (ARP); University of Michigan Comprehensive Depression Center Rachel Upjohn Clinical Scholars Award (ARP); R01 DA 022520, R01 DA 027492 and the Phil F. Jenkins Foundation (JKZ).

\section{ACKNOWLEDGEMENTS}

Virginia Murphy-Weinberg, Tiffany Love, Heng Wang, Marta Pecina, MBNI staff, Jill Rothley, Edward McKenna, Andrew Weeden, Paul Kison, Shayna Huber. Presented in part at the annual meeting of the American College of Neuropsychopharmacology, (2010, Miami, FL) and the Psychoneuroimmunology Research Society (2010, Dublin, Ireland) (ARP).

\section{REFERENCES}

Ahmed MS, Llanos QJ, Dinarello CA, Blatteis CM (1985). Interleukin 1 reduces opioid binding in guinea pig brain. Peptides 6: 1149-1154.

Angst J, Clayton P (1986). Premorbid personality of depressive, bipolar, and schizophrenic patients with special reference to suicidal issues. Compr Psychiatry 27: 511-532.

Anisman H, Zalcman S, Zacharko RM (1993). The impact of stressors on immune and central neurotransmitter activity: bidirectional communication. Rev Neurosci 4: 147-180.

Berkley KJ, Zalcman SS, Simon VR (2006). Sex and gender differences in pain and inflammation: a rapidly maturing field. Am J Physiol 291: R241-R244.

Buller KM, Hamlin AS, Osborne PB (2005). Dissection of peripheral and central endogenous opioid modulation of systemic interleukin-1beta responses using c-fos expression in the rat brain. Neuropharmacology 49: 230-242.

Carrasquillo Y, Gereau RWt (2007). Activation of the extracellular signal-regulated kinase in the amygdala modulates pain perception. J Neurosci 27: 1543-1551.

Cawthorne C, Prenant C, Smigova A, Julyan P, Maroy R, Herholz K et al (2011). Biodistribution, pharmacokinetics and metabolism of interleukin-1 receptor antagonist (IL-1RA) using [(1)(8)F]IL1RA and PET imaging in rats. Br J Pharmacol 162: 659-672.

Costa PT Jr., McCrae RR (1992). Revised NEO Personality Inventory and Five-Factor Inventory professional manual. Psychological Assessment Resources: Odessa, FL.

Dantzer R, O'Connor JC, Freund GG, Johnson RW, Kelley KW (2008). From inflammation to sickness and depression: when the immune system subjugates the brain. Nat Rev Neurosci 9: 46-56.
Day HE, Akil H (1996). Differential pattern of c-fos mRNA in rat brain following central and systemic administration of interleukin-1-beta: implications for mechanism of action. Neuroendocrinology 63: 207-218.

Day HE, Akil H (1999a). Evidence that cholecystokinin receptors are not involved in the hypothalamic-pituitary-adrenal response to intraperitoneal administration of interleukin-1beta. J Neuroendocrinol 11: 561-568.

Day HE, Curran EJ, Watson SJ Jr., Akil H (1999b). Distinct neurochemical populations in the rat central nucleus of the amygdala and bed nucleus of the stria terminalis: evidence for their selective activation by interleukin-1beta. J Comp Neurol 413: 113-128.

First MB, Spitzer R (1995): Structured Clinical Interview for DSMIV Axis I Disorders (SCID-I).

Friston KJ WK, Frackowiak RSJ, Mazziotta JC, Evans AC (1994). Assessing the significance of focal activations using their spatial extent. Hum Brain Mapp 1: 210-220.

Gear RW, Aley KO, Levine JD (1999). Pain-induced analgesia mediated by mesolimbic reward circuits. J Neurosci 19: 7175-7181.

Gear RW, Levine JD (1995). Antinociception produced by an ascending spino-supraspinal pathway. $J$ Neurosci 15: 3154-3161.

Goadsby PJ (2005). Can we develop neurally acting drugs for the treatment of migraine? Nat Rev Drug Discov 4: 741-750.

Gur A, Oktayoglu P (2008). Status of immune mediators in fibromyalgia. Curr Pain Headache Rep 12: 175-181.

Harris RE, Clauw DJ, Scott DJ, McLean SA, Gracely RH, Zubieta JK (2007). Decreased central mu-opioid receptor availability in fibromyalgia. J Neurosci 27: 10000-10006.

Hayes AF (2012). PROCESS: A versatile computational tool for observed variable mediation, moderation, and conditional process modeling.

Hutchinson MR, Coats BD, Lewis SS, Zhang Y, Sprunger DB, Rezvani $\mathrm{N}$ et al (2008). Proinflammatory cytokines oppose opioid-induced acute and chronic analgesia. Brain Behav Immun 22: 1178-1189.

Hutchinson MR, Shavit Y, Grace PM, Rice KC, Maier SF, Watkins LR (2011). Exploring the neuroimmunopharmacology of opioids: an integrative review of mechanisms of central immune signaling and their implications for opioid analgesia. Pharmacol Rev 63: 772-810.

Jones AK, Cunningham VJ, Ha-Kawa S, Fujiwara T, Luthra SK, Silva $S$ et al (1994). Changes in central opioid receptor binding in relation to inflammation and pain in patients with rheumatoid arthritis. Br J Rheumatol 33: 909-916.

Kennedy SE, Koeppe RA, Young EA, Zubieta JK (2006). Dysregulation of endogenous opioid emotion regulation circuitry in major depression in women. Arch Gen Psychiatry 63: 1199-1208.

Liberzon I, Zubieta JK, Fig LM, Phan KL, Koeppe RA, Taylor SF (2002). mu-Opioid receptors and limbic responses to aversive emotional stimuli. Proc Natl Acad Sci USA 99: 7084-7089.

Logan J, Fowler JS, Volkow ND, Wang GJ, Ding YS, Alexoff DL (1996). Distribution volume ratios without blood sampling from graphical analysis of PET data. J Cereb Blood Flow Metab 16: 834-840.

Melzack R (1975). The McGill Pain Questionnaire: major properties and scoring methods. Pain 1: 277-299.

Meyer CR, Boes JL, Kim B, Bland PH, Zasadny KR, Kison PV et al (1997). Demonstration of accuracy and clinical versatility of mutual information for automatic multimodality image fusion using affine and thin-plate spline warped geometric deformations. Med Image Anal 1: 195-206.

Miller AH, Maletic V, Raison CL (2009). Inflammation and its discontents: the role of cytokines in the pathophysiology of major depression. Biol Psychiatry 65: 732-741. 
Narendran R, Martinez D (2008). Cocaine abuse and sensitization of striatal dopamine transmission: a critical review of the preclinical and clinical imaging literature. Synapse 62: 851-869.

Neugebauer V, Li W, Bird GC, Han JS (2004). The amygdala and persistent pain. Neuroscientist 10: 221-234.

Paine P, Kishor J, Worthen SF, Gregory LJ, Aziz Q (2009). Exploring relationships for visceral and somatic pain with autonomic control and personality. Pain 144: 236-244.

Pauli P, Wiedemann G, Nickola M (1999). Pain sensitivity, cerebral laterality, and negative affect. Pain 80: 359-364.

Peterson PK, Molitor TW, Chao CC (1998). The opioid-cytokine connection. J Neuroimmunol 83: 63-69.

Prossin AR, Koch AE, Campbell PL, McInnis MG, Zalcman SS, Zubieta JK (2011). Association of plasma interleukin-18 levels with emotion regulation and mu-opioid neurotransmitter function in major depression and healthy volunteers. Biol Psychiatry 69: 808-812.

Prossin AR, Love TM, Koeppe RA, Zubieta JK, Silk KR (2010). Dysregulation of regional endogenous opioid function in borderline personality disorder. Am J Psychiatry 167: 925-933.

Raghavendra V, Rutkowski MD, DeLeo JA (2002). The role of spinal neuroimmune activation in morphine tolerance/hyperalgesia in neuropathic and sham-operated rats. J Neurosci 22: 9980-9989.

Ray R, Ruparel K, Newberg A, Wileyto EP, Loughead JW, Divgi C et al (2011). Human $\mathrm{Mu}$ opioid receptor (OPRM1 A118G) polymorphism is associated with brain mu-opioid receptor binding potential in smokers. Proc Natl Acad Sci USA 108: 9268-9273.

Renner F, Penninx BW, Peeters F, Cuijpers P, Huibers MJ (2013). Two-year stability and change of neuroticism and extraversion in treated and untreated persons with depression: Findings from the Netherlands Study of Depression and Anxiety (NESDA). J Affect Disord 150: 201-208.

Resendez SL, Dome M, Gormley G, Franco D, Nevarez N, Hamid AA et al (2013). mu-Opioid receptors within subregions of the striatum mediate pair bond formation through parallel yet distinct reward mechanisms. J Neurosci 33: 9140-9149.

Rohleder N, Wolf JM, Herpfer I, Fiebich BL, Kirschbaum C, Lieb K (2006). No response of plasma substance P, but delayed increase of interleukin-1 receptor antagonist to acute psychosocial stress. Life Sci 78: 3082-3089.

Ruzicka BB, Akil H (1997). The interleukin-1beta-mediated regulation of proenkephalin and opioid receptor messenger RNA in primary astrocyte-enriched cultures. Neuroscience 79: 517-524.
Salemi S, Rethage J, Wollina U, Michel BA, Gay RE, Gay S et al (2003). Detection of interleukin 1beta (IL-1beta), IL-6, and tumor necrosis factor-alpha in skin of patients with fibromyalgia. J Rheumatol 30: 146-150.

Shavit Y, Wolf G, Goshen I, Livshits D, Yirmiya R (2005). Interleukin-1 antagonizes morphine analgesia and underlies morphine tolerance. Pain 115: 50-59.

Uceyler N, Hauser W, Sommer C (2011). Systematic review with meta-analysis: cytokines in fibromyalgia syndrome. $B M C$ Musculoskelet Disord 12: 245.

Uceyler N, Valenza R, Stock M, Schedel R, Sprotte G, Sommer C (2006). Reduced levels of antiinflammatory cytokines in patients with chronic widespread pain. Arthritis Rheum 54: 2656-2664.

Vallejo R, de Leon-Casasola O, Benyamin R (2004). Opioid therapy and immunosuppression: a review. Am J Ther 11: 354-365.

Vassend O, Roysamb E, Nielsen CS (2013). Five-factor personality traits and pain sensitivity: a twin study. Pain 154: 722-728.

Watkins LR, Wiertelak EP, Goehler LE, Smith KP, Martin D, Maier SF (1994). Characterization of cytokine-induced hyperalgesia. Brain Res 654: 15-26.

Watson D, Clark LA, Tellegen A (1988). Development and validation of brief measures of positive and negative affect: the PANAS scales. J Pers Soc Psychol 54: 1063-1070.

Worsley KJ, Poline JB, Vandal AC, Friston KJ (1995). Tests for distributed, nonfocal brain activations. Neuroimage 2: 183-194.

Yamakawa K, Matsunaga M, Isowa T, Kimura K, Kasugai K, Yoneda $\mathrm{M}$ et al (2009). Transient responses of inflammatory cytokines in acute stress. Biol Psychol 82: 25-32.

Yasuno F, Sanabria SM, Burns D, Hargreaves RJ, Ghose S, Ichise M et al (2007). PET imaging of neurokinin-1 receptors with [(18)F]SPA-RQ in human subjects: assessment of reference tissue models and their test-retest reproducibility. Synapse 61: 242-251.

Zautra AJ, Parrish BP, Van Puymbroeck CM, Tennen H, Davis MC, Reich JW et al (2007). Depression history, stress, and pain in rheumatoid arthritis patients. J Behav Med 30: 187-197.

Zubieta JK, Smith YR, Bueller JA, Xu Y, Kilbourn MR, Jewett DM et al (2001). Regional mu opioid receptor regulation of sensory and affective dimensions of pain. Science (New York, NY) 293: 311-315.

Zubieta JK, Smith YR, Bueller JA, Xu Y, Kilbourn MR, Jewett DM et al (2002). mu-opioid receptor-mediated antinociceptive responses differ in men and women. J Neurosci 22: 5100-5107.

Zubieta JK, Stohler CS (2009). Neurobiological mechanisms of placebo responses. Ann N Y Acad Sci 1156: 198-210. 